\title{
Cytoplasmic Cyclin E and Phospho-Cyclin- Dependent Kinase 2 Are Biomarkers of Aggressive Breast Cancer
}

Cansu Karakas, ${ }^{*}$ Anna Biernacka, ${ }^{\dagger}$ Tuyen Bui, ${ }^{*}$ Aysegul A. Sahin, ${ }^{\ddagger}$ Min Yi, ${ }^{\S}$ Said Akli, ${ }^{*}$ Jolie Schafer, ${ }^{*}$ Angela Alexander, ${ }^{*}$ Opoku Adjapong, ${ }^{\ddagger}$ Kelly K. Hunt, ${ }^{\S}$ and Khandan Keyomarsi*

From the Departments of Experimental Radiation Oncology,* Pathology and Immunology, ${ }^{\ddagger}$ and Surgical Oncology, ${ }^{\S}$ The University of Texas MD Anderson Cancer Center, Houston; and the Department of Pathology, ${ }^{\dagger}$ Baylor College of Medicine, Houston, Texas

Accepted for publication

February 29, 2016.

Address correspondence to Khandan Keyomarsi, Ph.D., or Cansu Karakas, M.D., Department of Experimental Radiation Oncology, Unit 66, The University of Texas MD Anderson Cancer Center, 1515 Holcombe Blvd., Houston, TX 77030. E-mail: kkeyomar@mdanderson.org or ckarakas@mdanderson.org.

\begin{abstract}
Cyclin $E$ and its co-activator, phospho-cyclin-dependent kinase 2 ( $p$-CDK2), regulate $G_{1}$ to $S$ phase transition and their deregulation induces oncogenesis. Immunohistochemical assessments of these proteins in cancer have been reported but were based only on their nuclear expression. However, the oncogenic forms of cyclin E (low molecular weight cyclin E or LMW-E) in complex with CDK2 are preferentially mislocalized to the cytoplasm. Here, we used separate nuclear and cytoplasmic scoring systems for both cyclin E and p-CDK2 expression to demonstrate altered cellular accumulation of these proteins using immunohistochemical analysis. We examined the specificity of different cyclin $E$ antibodies and evaluated their concordance between immunohistochemical and Western blot analyses in a panel of 14 breast cell lines. Nuclear versus cytoplasmic staining of cyclin E readily differentiated fulllength from LMW-E, respectively. We also evaluated the expression of cyclin E and p-CDK2 in 1676 breast carcinoma patients by immunohistochemistry. Cytoplasmic cyclin E correlated strongly with cytoplasmic p-CDK2 $(P<0.0001)$, high tumor grade, negative estrogen/progesterone receptor status, and human epidermal growth factor receptor 2 positivity (all $P<0.0001$ ). In multivariable analysis, cytoplasmic cyclin E plus phosphorylated CDK2 (as one variable) predicted breast cancer recurrence-free and overall survival. These results suggest that cytoplasmic cyclin E and p-CDK2 can be readily detected with immunohistochemistry and used as clinical biomarkers for aggressive breast cancer. (Am J Pathol 2016, 186: 1900-1912; http://dx.doi.org/10.1016/j.ajpath.2016.02.024)
\end{abstract}

Cyclin $\mathrm{E}$ and its kinase partner cyclin-dependent kinase 2 (CDK2) positively regulate the transition of cells from $G_{1}$ to $\mathrm{S}$ phase of the cell cycle, committing the cells to undergo cell division. ${ }^{1}$ Deregulated expression of cyclin $\mathrm{E}$ is associated with tumorigenesis and metastasis in preclinical studies and poor prognosis in clinical studies for several types of cancer, including breast cancer. ${ }^{2-8}$ In addition to regulating $\mathrm{G}_{1} / \mathrm{S}$ transition, cyclin $\mathrm{E} / \mathrm{CDK} 2$ complex directly phosphorylates proteins involved in several other cellular functions such as centrosome duplication, DNA repair, and histone gene transcription. ${ }^{1,9,10}$ Deregulation of cyclin $\mathrm{E}$ is due to a number of factors such as gene amplification, protein overexpression, mRNA stability, and posttranslational modification. One such post-translational modification is the proteolytic cleavage of full-length cyclin E (EL) to generate its low molecular weight (LMW-E) forms by the neutrophil elastase family of serine proteases. ${ }^{11,12}$ Compared with EL (EL1: $50 \mathrm{kDa}$ ), LMW-E (EL2-4: $33-45 \mathrm{kDa}$ ) is uniquely expressed in tumor cells. Studies have shown that LMW-E promotes deregulation of the cell cycle, induces cancer stem cell reprogramming indicative of poorer overall survival in breast cancer patients, while coordinating an irreversible alteration of the mammary microenvironment that facilitates tumor progression and induction of a persistent DNA damage response through the induction of replication stress. ${ }^{13-16}$

Supported by NIH grants CA87458 and CA1522228 (K.K.) and CCSG grant P30 CA016672 (MD Anderson Cancer Center).

Disclosures: None declared. 
The significance of LMW-E, which was originally discovered in breast cancer by our group and subsequently by others, ${ }^{17-20}$ has recently been the subject of several review articles. ${ }^{21-23}$ These isoforms are also found in ovarian cancer, ${ }^{4,24}$ melanomas, ${ }^{2}$ gastric cancer, ${ }^{25}$ colorectal cancer, ${ }^{26-28}$ lung cancer, ${ }^{29}$ and renal cell carcinomas ${ }^{30}$ and are strongly associated with poor survival in patients. ${ }^{4,26,31}$ Work from our laboratory has implicated LMW-E in breast cancer oncogenesis. For example, LMW-E i) is biochemically hyperactive because of its increased affinity for cdk 2 and resistance to inhibition by the CDK inhibitors p21 and p27 $7^{32}$;ii) is resistant to the growth-inhibiting effects of antiestrogens ${ }^{33}$ and aromatase inhibitors ${ }^{34}$; iii) promotes deregulation of cell cycle, ${ }^{35}$ centrosome amplification, ${ }^{13}$ and genomic instability ${ }^{33}$; iv) causes premature inactivation of Cdc25C and PLK1, leading to faster mitotic exit ${ }^{16}$; v) is sufficient to render human mammary epithelial cells tumorigenic and leads to altered acinar morphogenesis ${ }^{36}$; vi) phosphorylates Hbo1 to mediate a cancer stem cell-like environment ${ }^{14}$; and vii) is a downstream oncogenic target of protein kinase $\mathrm{Cl}^{37}$ Given its unique properties and distinct functions in human cancers, measuring the expression of LMW-E would be instrumental in stratifying patients for targeted therapy against LMW-E/CDK2.

One important difference between EL and LMW-E is the loss of the canonical $\mathrm{NH}_{2}$-terminal nuclear localization sequence in LMW-E isoforms, because the neutrophil elastase-mediated cleavage of the full-length protein occurs downstream of the nuclear localization sequence. ${ }^{38,39}$ As a result, LMW-E isoforms preferentially accumulate in the cytoplasm of cancer cells. ${ }^{35,39}$ The expression of cyclin E has been the subject of numerous clinical studies; however, these studies only captured the nuclear expression, resulting in a lack of consensus on the prognostic significance of cyclin E. ${ }^{3,5,6,31,40-51}$ One explanation for these results may be that the isoform of cyclin $\mathrm{E}$ that most likely is the prognostic indicator for breast cancer is the cytoplasmic and not the nuclear isoform.

Recently, Hunt et al (K.K.H., C.K., A.A.S., and K.K., unpublished data) examined the expression of nuclear and cytoplasmic cyclin E in 2510 breast cancer patients with the use of immunohistochemistry (IHC) whereby each sample was scored for its nuclear and cytoplasmic expression of cyclin E separately. The multivariate analysis revealed that cytoplasmic cyclin $\mathrm{E}$ is associated with the greatest risk of recurrence, outperforming all known prognostic factors. In this report we present the generation of the nuclear and cytoplasmic cyclin E scoring system in breast cancer cell lines and tumor tissues derived from cyclin $\mathrm{E}$ transgenic mice. In addition, we provide details about the specificity of several antibodies for cyclin E and identify the one that can specifically stain the cytoplasmic LMW-E protein. We also translated our findings to human breast cancer samples, in which we examined the expression of cytoplasmic cyclin $\mathrm{E}$ and phospho-CDK2 (p-CDK2; the catalytic partner of cyclin E) in 1676 breast cancer patients.

\section{Materials and Methods}

\section{Cell Lines}

Normal mammary epithelial cells (76NF2V and MCF-10A) and cell lines that represent the different molecular subtypes of breast cancer-luminal A (MCF-7, MCF-7T, and ZR75-1), luminal B (MDA-MB-361 and UACC812), human epidermal growth factor receptor 2 (HER2)/neu ${ }^{+}$(SKBR-3, AU565, and HCC1954), and triple-negative (MDA-MB-231, MDA-MB436, MDA-MB-468, and HCC1937) - were maintained in a humidified incubator at $37^{\circ} \mathrm{C}$ in a $6.5 \% \mathrm{CO}_{2}$ atmosphere. Human mammary epithelial cell lines (76NF2V and MCF10A) were cultured in DFCI-1 medium, which consists of $\alpha$-Minimum Essential Medium and Ham's F-12 medium (1:1 v/v) (HyClone Laboratories, Inc., Logan, UT) supplemented with $1 \%$ fetal bovine serum (Atlanta Biologicals, Norcross, GA), $0.01 \mathrm{~mol} / \mathrm{L}$ HEPES buffer, $2 \mathrm{mmol} / \mathrm{L}$ L-glutamine, 12.5 $\mathrm{ng} / \mathrm{mL}$ epidermal growth factor, $10 \mathrm{nmol} / \mathrm{L}$ triiodothyronine, $0.01 \mathrm{mmol} / \mathrm{L}$ ascorbic acid, $2 \mathrm{nmol} / \mathrm{L}$ estradiol, $1 \mu \mathrm{g} / \mathrm{mL}$ insulin, $1 \mathrm{mg} / \mathrm{mL}$ hydrocortisone, $0.1 \mathrm{mmol} / \mathrm{L}$ ethanolamine, $0.1 \mathrm{mmol} / \mathrm{L}$ phosphoethanolamine, $0.01 \mathrm{mg} / \mathrm{mL}$ transferrin, $2.5 \mathrm{ng} / \mathrm{mL}$ sodium selenite, $0.035 \mathrm{mg} / \mathrm{mL}$ bovine pituitary extract, and $0.01 \mathrm{mg} / \mathrm{mL}$ ciprofloxacin.

\section{Preparation of Protein Lysates}

Cells were harvested with trypsin. The cells were washed in phosphate-buffered saline (PBS) and resuspended in protease/phosphatase inhibition buffer that contained $25 \mathrm{~g} / \mathrm{mL}$ leupeptin, $25 \mathrm{~g} / \mathrm{mL}$ aprotinin, $10 \mathrm{~g} / \mathrm{mL}$ pepstatin, $1 \mathrm{mmol} / \mathrm{L}$ benzamidine, $10 \mathrm{~g} / \mathrm{mL}$ soybean trypsin inhibitor, $0.5 \mathrm{mmol} /$ $\mathrm{L}$ phenylmethylsulfonyl fluoride, $50 \mathrm{mmol} / \mathrm{L}$ sodium fluoride, and $0.5 \mathrm{mmol} / \mathrm{L}$ sodium orthovanadate. Cells were lysed by sonication (Sonicator XL; Misonix Inc., Farmingdale, NY), and the lysates were cleared by centrifugation at $125,000 \times g$ for 45 minutes at $4^{\circ} \mathrm{C}$. Protein concentration was determined by Bradford assay (reagents from Bio-Rad Laboratories, Hercules, CA). Protein concentration was normalized by addition of PBS, followed by addition of $2 \times$ Laemmli buffer (4\% SDS, $20 \%$ glycerol, $120 \mathrm{mmol} / \mathrm{L}$ TrisHCL, pH 6.8, and $0.02 \%$ bromophenol blue) to a final concentration of $2.5 \mu \mathrm{g} / \mu \mathrm{L}$ for Western blot analysis.

\section{Western Blot Analysis}

Cell lysates were subjected to Western blot analysis as described previously. ${ }^{31}$ Briefly, $50 \mu \mathrm{g}$ of protein from each condition being tested was loaded into the lanes of a $10 \%$ SDS-PAGE gel and submitted to electrophoresis for $300 \mathrm{~V}$ hours. These gels were then transferred to Immobilon $\mathrm{P}$ membrane (Millipore, Billerica, MA) by electrophoresis for $400 \mathrm{~V}$ hours at $4^{\circ} \mathrm{C}$. Each membrane was initially stained with Ponceau $\mathrm{S}$, to detect total protein loading on the Immobilon P membranes (Supplemental Figure S8). After Ponceau S destaining, the membranes were blocked for 1 
hour in BLOTTO $(5 \%$ nonfat dry milk in TBS-T; $20 \mathrm{mmol} / \mathrm{L}$

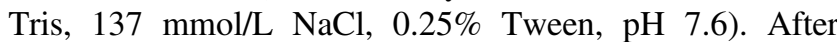
blocking, the membranes were incubated in primary antibodies (at a concentration of $0.1 \mu \mathrm{g} / \mathrm{mL}$ ) in BLOTTO for 3 hours at room temperature. The primary antibodies against cyclin $\mathrm{E}$ used are listed in Table 2. Antibody against actin (Chemicon International, Temecula, CA) was used as loading control. After incubation with primary antibody, the membranes were washed three times for 20 minutes in TBS$\mathrm{T}$ and then incubated with goat anti-mouse or anti-rabbit IgG-horseradish peroxidase-conjugated secondary antibodies (Pierce, Rockford, IL) at a dilution of 1:3000 in BLOTTO for 1 hour. The membrane was washed three times for 20 minutes in TBS-T and developed with the Renaissance chemiluminescence system (PerkinElmer Life Sciences, Inc., Waltham, MA). The membranes were placed in an autoradiography cassette, exposed to film, and scanned.

\section{Three-Dimensional Matrigel Cell Block Assay}

Normal mammary epithelial and breast cancer cells were harvested and fixed by adding $5 \mathrm{~mL}$ of $95 \%$ formalin, followed by $5 \mathrm{~mL}$ of $80 \%$ ethanol, resuspended and centrifuged for 10 minutes at $400 \times g$. All but $2 \mathrm{~mL}$ of the supernatant fluid was removed, and cells were resuspended in a 1:1 volume with Matrigel. The liquid sediment was transferred to a $15-\mathrm{mL}$ glass centrifuge tube coated in collodion. The cells were centrifuged for 7 minutes, supernatant fluid was poured off, and the collodion bag was removed from the tube with the use of forceps and placed on a $2 \times 2 \times 2$-cm section of shark skin filter paper and enclosed. The enclosed cell block was placed in a cassette and stored in $10 \%$ formalin until paraffin embedment. Cell line microarrays were constructed with 1-mm diameter cores from each cell block, sectioned $(4 \mu \mathrm{m})$, and assessed by IHC. Representative images of cyclin E immunohistochemical staining of cell line microarray with and without collodion Matrigel are shown in Supplemental Figure S1.

\section{Analysis of Murine Transgenic Mammary Tumors}

Transgenic mammary tumors were derived from three different lines of transgenic mice previously characterized in our laboratory. ${ }^{11}$ The transgenic constructs expressed in these three lines were i) mouse mammary tumor virus (MMTV)cyclin EL1/EL4, which, when expressed in mammary glands of transgenic mice, generates both EL1, the full-length form, and the EL4, a LMW-E isoform; ii) MMTV-cyclin E-M46A, which harbors a mutation at codon 46 that replaces methionine with alanine, thereby generating a construct that codes only for the full-length form; and iii) MMTV-cyclin E-Trunk 1 (T1), which codes for the LMW isoforms of cyclin E, EL2, and EL3. In total we analyzed samples from 30 cyclin E-transgenic mice that expressed EL alone (M46A; $n=6$ ), EL and its LMW-E EL4 isoforms (EL1/EL4; $n=8)$, or the LMW-E EL2/3 isoforms of cyclin $\mathrm{E}(n=16)$. Mammary tumor samples were fixed in 10\% neutral-buffered formalin, embedded in paraffin, and sectioned at $5 \mu \mathrm{m}$ for analysis by IHC.

\section{Pathology and Medical Record Review}

We used two patient cohorts for this study. The first was a cohort of 725 patients at The University of Texas MD Anderson Cancer Center (MDACC) with stage I to II breast cancer who underwent surgery between 1985 and 1999 and for whom tissue microarrays (TMAs) had been constructed by acquiring 1.0-mm biopsy cores from representative areas of breast tumors as previously described (MDACC TMA). ${ }^{52}$ In each TMA block, nonneoplastic breast tissue cores were also included as controls. The second cohort, purchased from the National Cancer Institute (NCI) Cancer Diagnosis Program, was a group of 951 patients with stage I to III breast cancer who underwent surgery between 1985 and 1997 at four different hospitals as follows: Kaiser Permanente (Portland, OR), Washington University (St. Louis, MO), Fox Chase Cancer Center (Philadelphia, PA), and University of Miami (Coral Gables, FL) (NCI TMA). TMAs for these patients were constructed at the University of Virginia for the NCI Cancer Diagnosis Program. Two cores of representative areas from each tumor $(0.6 \mathrm{~mm}$ in diameter $)$ and an additional normal breast/nonbreast and cell line tissue cores were used for microscopy examination. All research was conducted in accordance with ethical guidelines as described in institutional review board-approved protocol L. The clinical characteristics of the patients are listed in Table 1.

\section{Immunohistochemical Staining of Breast Tumor Samples for Cyclin E and p-CDK2}

Sections ( $5 \mu \mathrm{m}$ thick) of formalin-fixed, paraffin-embedded breast tumor samples were deparaffinized and rehydrated, followed by incubation with 3\% hydrogen peroxide and methanol to block endogenous peroxidase activity and nonspecific protein-protein interactions, respectively. Antigen retrieval was performed with $0.01 \mathrm{mmol} / \mathrm{L}$ citric acidbased buffer at $\mathrm{pH} 6.0$ with the use of a hot plate in a metal container for 15 minutes before immunostaining. After 1 hour blocking for nonspecific staining, the sections were incubated with six different mouse monoclonal antibodies and two rabbit polyclonal antibodies for cyclin E, and a rabbit polyclonal antibody for phospho p-CDK2 (Thr160; Cell Signaling Technology, Danvers, MA). The source of each antibody, dilutions, incubation period, and antigen retrieval process are described in Table 2. Antibodies were detected with a VECTASTAIN Elite ABC kit (PK6101 and PK6102; Vector Laboratories, Burlingame, CA). Cells positive for cyclin $\mathrm{E}$ and $\mathrm{p}-\mathrm{CDK} 2$ were visualized with the chromogenic substrate 3,3'-diaminobenzidine. Slides were counterstained with hematoxylin and mounted. Tumor cell blocks known to highly express LMW-E were included in each batch, and negative controls were prepared by replacing the primary antibody with PBS. All washing steps were performed with PBS alone first and then with PBS with $0.1 \%$ Tween. 
Table 1 Clinical and Pathologic Variables for the Two Patient Cohorts

\begin{tabular}{|c|c|c|c|c|}
\hline Factors & $\begin{array}{l}\text { NCI TMA } \\
(n=951)\end{array}$ & $\begin{array}{l}\text { MDACC TMA } \\
(n=725)\end{array}$ & $P$ value * & $\begin{array}{l}\text { Both cohorts } \\
(n=1676)\end{array}$ \\
\hline Median age, years (range) & $60(25-96)$ & $53(25-87)$ & $<0.0001$ & $56(25-96)$ \\
\hline Histology, $n(\%)$ & & & 0.2 & \\
\hline IDC & $815(85.7)$ & $622(85.8)$ & & $1437(85.7)$ \\
\hline ILC & $91(9.6)$ & $57(7.9)$ & & $148(8.8)$ \\
\hline Other & $45(4.7)$ & $46(6.3)$ & & $91(5.4)$ \\
\hline II & $443(46.6)$ & $306(42.6)$ & & $749(44.9)$ \\
\hline III & $277(29.1)$ & $197(27.5)$ & & $474(28.4)$ \\
\hline Unknown & 0 & 7 & & 7 \\
\hline Cyclin E staining, $n(\%)$ & & & $<0.0001$ & \\
\hline No staining & $113(11.9)$ & $58(8.0)$ & & $171(10.2)$ \\
\hline Nuclear & $244(25.7)$ & $240(33.1)$ & & $484(28.9)$ \\
\hline Negative & $357(37.5)$ & $298(41.1)$ & & $655(39.1)$ \\
\hline Positive & $594(62.5)$ & $427(58.9)$ & & $1021(60.9)$ \\
\hline Cytoplasmic staining for $\mathrm{p}-\mathrm{CDK} 2, n(\%)$ & & & 0.4 & \\
\hline Negative & $377(39.6)$ & $301(41.5)$ & & $678(40.4)$ \\
\hline Positive & $574(60.4)$ & $424(58.5)$ & & $998(59.6)$ \\
\hline ER status, $n(\%)$ & & & 0.001 & \\
\hline Positive & $701(74.5)$ & $488(67.4)$ & & $1189(71.4)$ \\
\hline Negative & $240(25.5)$ & $236(32.6)$ & & $476(28.6)$ \\
\hline Unknown & 10 & 1 & & 11 \\
\hline PR status, $n(\%)$ & & & $<0.0001$ & \\
\hline Positive & $630(66.7)$ & $413(57.0)$ & & $1043(62.5)$ \\
\hline
\end{tabular}

*P values were calculated after excluding unknown category.

ER, estrogen receptor; HER2, human epidermal growth factor receptor 2; IDC, invasive ductal carcinoma; ILC, invasive lobular carcinoma; MDACC, MD Anderson Cancer Center; NCI, National Cancer Institute; p-CDK2, phospho-cyclin-dependent kinase 2; PR, progesterone receptor; TMA, tissue microarray.

\section{Scoring of Breast Tumor Sections}

Only tumors with $>5 \%$ nuclear or cytoplasmic positivity were considered as cyclin $\mathrm{E}^{+}$or $\mathrm{p}-\mathrm{CDK} 2^{+}$.

\section{Cyclin E Scoring}

Nuclear and cytoplasmic staining scores were independently assigned according to their staining intensity $(1=$ no

Table 2 List of Cyclin E Antibodies Used for Immunohistochemistry and Western Blot Analysis

\begin{tabular}{lllllll}
\hline Clone number & Vendor & Host/Isotype & Catalog No. & Titer & Incubation & Antigen retrieval \\
\hline C19 & Santa Cruz & Rabbit/polyclonal & Sc-198 & $1: 1000$ & ON, $4^{\circ} \mathrm{C}$ & HIAR-pH $=6,20$ minutes \\
HE-12 & Santa Cruz & Mouse/monoclonal & Sc-247 & $1: 400$ & ON, $4^{\circ} \mathrm{C}$ & HIAR-pH $=6,15$ minutes \\
6 A59 & Santa Cruz & Mouse/monoclonal & Sc-70901 & $1: 150$ & 1 hour, RT & HIAR-pH $=6,20$ minutes \\
HE-172 & MBL & Mouse/monoclonal & K0173-3 & $1: 300$ & 1 hour, RT & HIAR-pH $=6,15$ minutes \\
HE67 & BD Pharmingen & Mouse/monoclonal & 554192 & $1: 500$ & 1 hour, RT & HIAR-pH $=6,20$ minutes \\
HE-111 & Santa Cruz & Mouse/monoclonal & Sc-248 & $1: 100$ & ON, $4^{\circ} \mathrm{C}$ & HIAR-pH $=6,15$ minutes \\
13A3 & Leica Biosystems & Mouse/monoclonal & Ncl-Cyclin E & $1: 40$ & 30 minutes, RT & HIAR-pH $=6,20$ minutes \\
M-20 & Santa Cruz & Rabbit/polyclonal & Sc-481 & $1: 500$ & 30 minutes, RT & HIAR-pH $=6,20$ minutes \\
\hline
\end{tabular}

HIAR, heat-induced antigen retrieval; $0 \mathrm{~N}$, overnight; RT, room temperature. 
staining, $2=$ weak staining, $3=$ intermediate staining, and $4=$ strong staining) (Supplemental Figures S2 and S3). The nuclear and cytoplasmic scores were combined to generate the four cyclin E immunophenotypes as depicted in Supplemental Figure S4. Phenotype 1 indicated no nuclear and no cytoplasmic staining; phenotype 2, positive nuclear staining and no or weak cytoplasmic staining; phenotype 3, positive nuclear and positive cytoplasmic staining; phenotype 4, positive cytoplasmic and no or weak nuclear staining. For example, cases with nuclear score of 1 or 2 and cytoplasmic score of 3 or 4 will fall under the phenotype 4 category. Three different pathologists (C.K., A.B., and O.A.) scored each slide for nuclear and cytoplasmic staining of cyclin $\mathrm{E}$ and p-CDK2, blinded to patients' clinical histories and outcomes. Percentage of interobserver agreement for cyclin E scoring by IHC was at $90 \%$ ( $\kappa$ test) for both cohorts (Supplemental Table S1).

\section{p-CDK2 Staining}

The intensity of nuclear staining was scored semiquantitatively on a scale of 0 to $3(0=$ no staining, $1=$ weak staining, $2=$ moderate staining, and $3=$ strong staining). The extent of nuclear staining was classified as the percentage of cells with p-CDK2 ${ }^{+}$nuclei on a scale of 0 to 6 as follows: $0 \%=0,1 \%$ to $5 \%=1,6 \%$ to $10 \%=2,11 \%$ to $25 \%=3,26 \%$ to $50 \%=4,51 \%$ to $75 \%=5$, and $76 \%$ to $100 \%=6$. The final immunoreactivity score was determined by multiplying the intensity score by the staining extent score, with a minimum score of 0 and maximum score of 18; scores of $\geq 6$ indicated positivity. Cytoplasmic staining for $\mathrm{p}-\mathrm{CDK} 2$ was scored in a binary fashion as positive or negative (Supplemental Figure S5 and S6).

Data on estrogen receptor (ER), progesterone receptor (PR), and HER2 status were obtained by standard clinical testing with the use of IHC according to guidelines by the American Society of Clinical Oncology and the College of American Pathologists. ${ }^{53}$ Cells were determined to be positive for ER and PR if at least $1 \%$ of the cells exhibited nuclear staining for these two receptors. Staining for HER2 was scored as negative, indeterminate $\left(1\right.$ to $\left.2^{+}\right)$, or positive $\left[3^{+}\right.$(overexpression)]. Cases with HER2 immunostaining scores of $2^{+}$were subsequently assessed with fluorescence in situ hybridization.

\section{Statistical Analysis}

\section{Mouse Transgenic Tumors}

Fisher exact test was used to determine the differences in frequency of cytoplasmic cyclin $\mathrm{E}$ immunostaining (positive versus negative) among given phenotypes.

\section{Patient Samples}

Tumor characteristics were evaluated and compared between the cohort A (NCI TMA) and cohort B (MDACC TMA). The relations between nuclear cyclin E, cytoplasmic cyclin E, cytoplasmic p-CDK2 immunostaining scores and histologic grade, ER, PR, and HER2 status were evaluated.
The $\chi^{2}$ test or Fisher exact test was used for univariate comparison of categorical variables. $\kappa$ statistic and weighted $\kappa$ statistic were used to evaluate the agreement among pathologists. $\kappa$ Statistic is standardized to lie on a -1 to 1 scale, where 1 is perfect agreement, 0.81 to 0.99 is almost perfect agreement, 0 is exactly what would be expected by chance, and negative values indicate agreement less than chance (ie, potential systematic disagreement between the observers). Stata SE statistical software version 12.0 (StataCorp LP, College Station, TX) was used for statistical analyses. All tests were two-tailed, and statistical significance was set at $P<0.05$. End points were recurrence-free survival and overall survival and were calculated from the time of surgery to breast cancer recurrence. Stratified multivariate analysis of factors associated with differences in recurrence-free survival was performed with a Cox proportional hazards model to assess whether the univariate significance of cyclin E and p-CDK2 can be explained by their association with known prognostic factors (Table 3).

\section{Results}

Identification of Anti-Cyclin E Antibodies that Differentiate Nuclear and Cytoplasmic Cyclin E Expression

Most clinical studies that reported on the expression of cyclin $\mathrm{E}$ in breast tumor tissue samples by analysis with IHC used eight different cyclin E antibodies (Table 2, Supplemental Table S2). Collectively, a total of 2641 patients diagnosed with invasive breast cancer were examined for the expression of nuclear cyclin $\mathrm{E}$ with the use of these antibodies. Although cytoplasmic staining of cyclin E was noted in a few of these studies, it was not used in linking it

Table 3 Stratified Multivariate Cox Proportional Hazards Analysis of Clinicopathologic Variables' Influence on Breast Cancer Recurrence-Free Survival

\begin{tabular}{lllll}
\hline Factor & Hazard ratio & SEM & $P$ value & $95 \%$ CI \\
\hline $\begin{array}{l}\text { Combined cytoplasmic } \\
\quad \text { staining for cyclin }\end{array}$ & & & & \\
$\quad \begin{array}{llll}\text { E and p-CDK2 } \\
\text { Both negative }\end{array}$ & Referent & & & \\
$\quad$ One positive & 3.1 & 0.6 & $<0.0001$ & $2.2-4.5$ \\
$\quad$ Both positive & 4.3 & 0.7 & $<0.0001$ & $3.1-5.9$ \\
Histologic grade & & & & \\
I & Referent & & & \\
II & 1.1 & 0.2 & 0.4 & $0.9-1.5$ \\
III & 1.4 & 0.2 & 0.02 & $1.1-1.9$ \\
Histologic findings & & & & \\
IDC & & & & \\
ILC & 1.7 & 0.3 & 0.001 & $1.2-2.4$ \\
Other & 0.6 & 0.2 & 0.08 & $0.4-1.1$ \\
Age & 1.0 & 0.0 & 0.005 & $1.0-1.0$ \\
\hline
\end{tabular}

IDC, invasive ductal carcinoma; ILC, invasive lobular carcinoma; p-CDK2, phospho-cyclin-dependent kinase 2. 
A
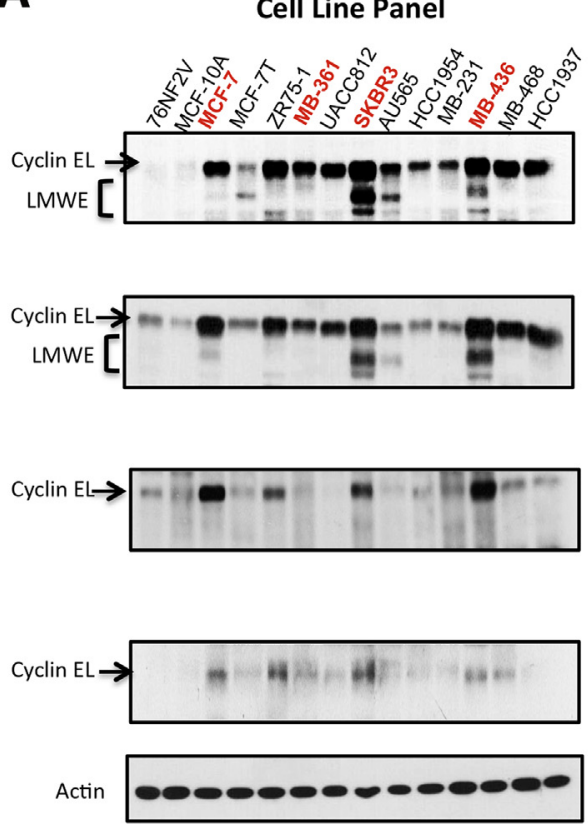

B

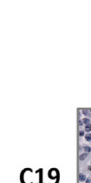

MCF7

$\mathrm{ER}+/ \mathrm{Her} 2$ -
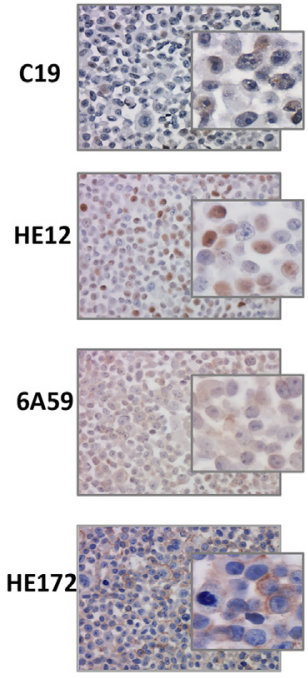

MDA-MB-361

$\mathrm{ER}+/ \mathrm{Her} 2+$
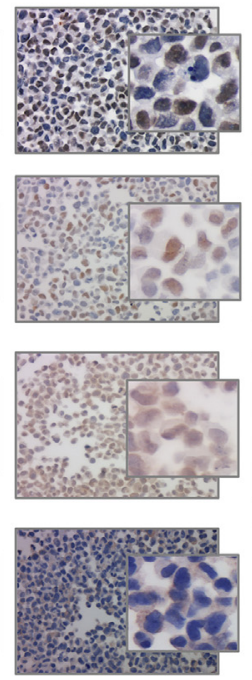

SKBR3

ER-/Her2+
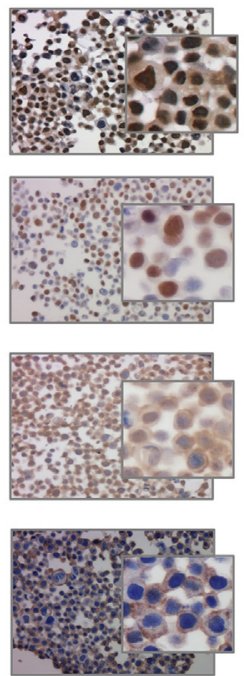

MDA-MB-436

Triple Negative
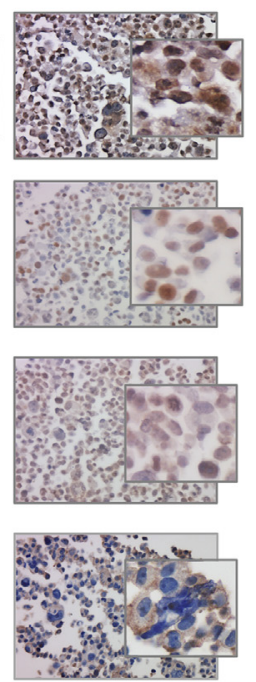

Figure 1 Detection of cyclin E by Western blot and IHC analyses across four different antibodies in breast cancer cell lines. A: Western blot analysis of 14 different normal and breast cancer cell lines with the indicated four different antibodies. A single actin blot from the gel used for the 6 A59 is used as a control. To confirm equal loading and transfer efficiency, Ponceau S staining for loading control of membranes used in the experiment are shown in Supplemental Figure S8. The four cell lines highlighted in red were subjected to IHC analysis. B: IHC staining of the four different antibodies in four different cell lines. Rows indicate antibodies against the different cyclin E epitopes; columns, breast tumor cell lines with their hormonal status. Results show false-negative and false-positive immunostaining of cyclin E monoclonal antibodies compared with polyclonal antibody C-19. Source of antibodies and dilution used for Western blot and IHC analyses are shown in Table 2. Original magnification: $\times 200$ (main images); $\times 800$ (insets). EL, full-length cyclin E; ER, estrogen receptor; HER2, human epidermal growth factor receptor 2; IHC, immunohistochemical; LMWE, low molecular weight cyclin E.

to clinical outcome. To identify which of these antibodies is suitable for differentiating EL from LMW-E by Western blot analysis, we used these eight antibodies in two different systems as follows: MCF-7 panel that comprises five different cell lines that are parental vector alone control transfected with EL or the LMW-E forms (T1 and T2) and an in vitro expression system called transcription and translation assay where plasmids harboring EL and LMW-E (T1 and T2) isoforms were subjected to a transcription and translation assay that generated protein products for each of the isoforms (Supplemental Figure S7). The MCF-7 panel and the transcription and translation products from each of the isoforms were subjected to Western blot analysis on the same gel to allow for side-by-side comparison. The results showed that all antibodies, except for $13 \mathrm{~A} 3$ and M20, could detect both EL and LMW-E. 13A3 and M20 detect only the EL but not the LMW forms of cyclin E.

We next examined the expression of endogenous cyclin $\mathrm{E}$ in a panel of 14 normal and breast cancer cell lines by Western blot analysis with the eight different cyclin $\mathrm{E}$ antibodies (Figures 1 and 2). Equal loading was assessed by Actin (Figures 1 and 2) or Ponceau staining of each blot (Supplemental Figure S8). HE-12 antibody, which is commonly used to detect cyclin E by Western blot analysis, revealed that, although EL was expressed in all cell lines, LMW-E was expressed only in three of the tumor cell lines (SKBR3, AU565, and MDA-MB-436) as previously reported. $^{54,55}$ The only other antibody that showed similar pattern of full-length and LMW-E expression was the C-19 antibody (Figure 1). We next interrogated which one of the eight antibodies could differentially detect full-length (nuclear) and LMW-E (cytoplasmic) by immunostaining. To this end we used two cell lines, which showed expression of EL (MCF-7 and MDA-MB-361) and two cell lines with LMW-E (SKBR3 and MDA-MB-436) as detected by HE-12 and C-19 antibodies. We generated cell blocks from each of the four cell lines and subjected them to analysis by IHC with the eight different antibodies (Figures 1 and 2). The results revealed that, of all of the antibodies examined, only the C19 antibody detected differential expression of nuclear and cytoplasmic staining by IHC that correlated with EL and LMW-E by Western blot analysis. Specifically, C-19 antibody detected predominately nuclear staining in MCF-7 and MDA-MB-361 and nuclear and cytoplasmic cyclin E staining in SKBR3 and MDA-MB-436 cell lines. None of the other seven antibodies showed specific nuclear and cytoplasmic staining (by IHC) that corresponded to EL and LMW-E expressions (by Western blot analysis).

Cyclin E Expression in Mammary Tumors Obtained from EL and LMW-E-Overexpressing Transgenic Mice

With the aim of determining whether cytoplasmic staining for cyclin $\mathrm{E}$ in routine IHC is a surrogate for that in Western blot 
A
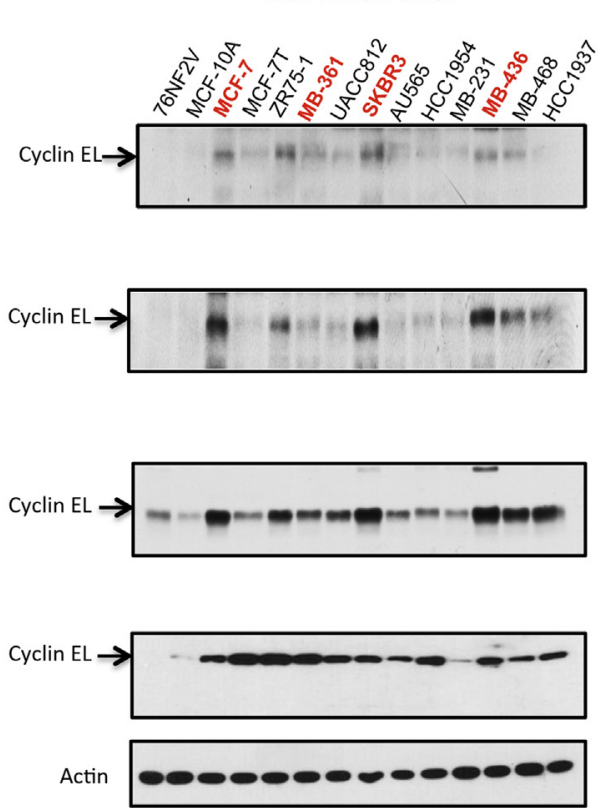

B
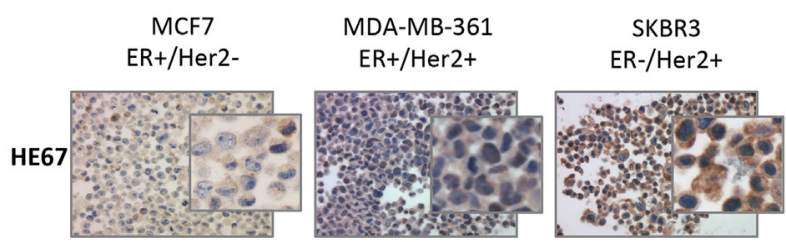

MDA-MB-436

Triple Negative
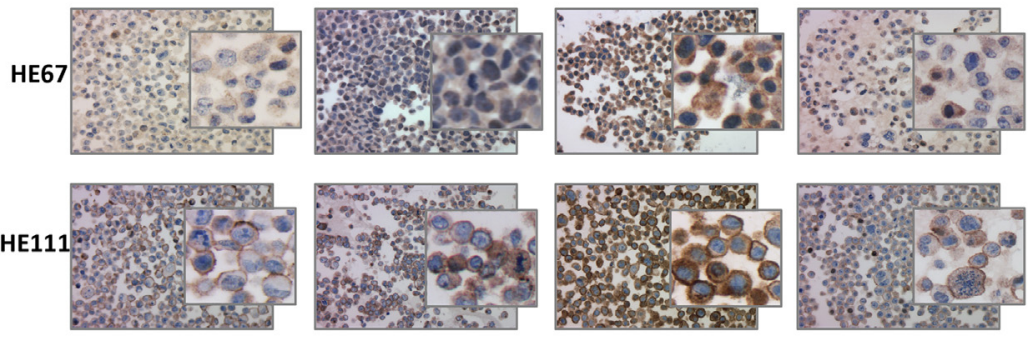

$13 \mathrm{A3}$
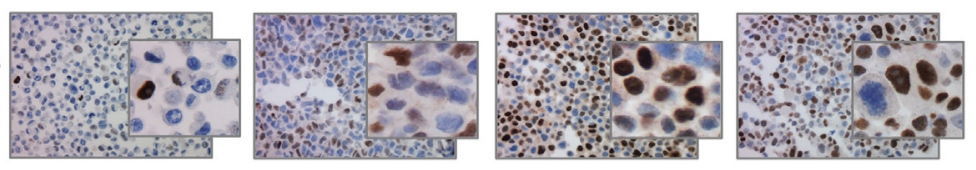

M20
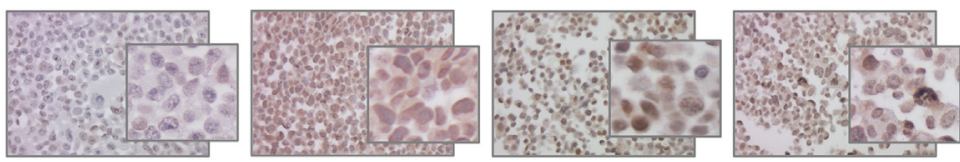

Figure 2 Detection of cyclin E by Western blot and IHC analyses across four different antibodies in breast cancer cell lines. A: Western blot analysis of 14 different normal and breast cancer cell lines with the indicated four different antibodies. The same actin blot from Figure 1 is used as a control, and the Ponceau S-stained membranes are shown in Supplemental Figure S8 to confirm loading on each gel. The four cell lines highlighted in red were subjected to IHC analysis. B: IHC staining of the four different antibodies in four different cell lines. Rows indicate antibodies against the different cyclin E epitopes; columns, breast tumor cell lines with their hormonal status. Source of antibodies and dilution used for Western blot and IHC analyses are shown in Table 2. Original magnification: $\times 200$ (main images); $\times 800$ (insets). EL, full-length cyclin E; ER, estrogen receptor; HER2, human epidermal growth factor receptor 2; IHC, immunohistochemical.

analysis for detection of LMW-E, we examined human cyclin E expression in vivo with the use of mammary tumors generated from cyclin E-transgenic mice. ${ }^{11}$ Tumor tissues generated from several strains of EL (M46A) and LMW-E (EL1/EL4; T1) transgenic mice were subjected to Western blot analysis and IHC for cyclin E with the use of the HE-12 and C-19 antibodies, respectively (Figure 3). Because cyclin $\mathrm{E}$ deregulation is an early event in the tumorigenesis process, some of the LMW-E transgenic mice (391 and 520) lost cyclin $\mathrm{E}$ expression ${ }^{11}$ and were used as negative control for
A

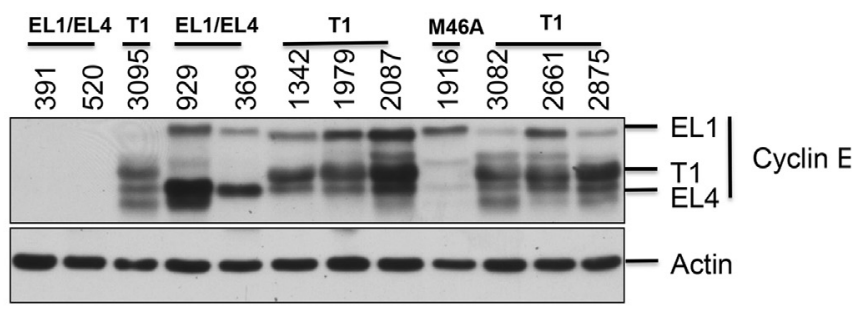

B
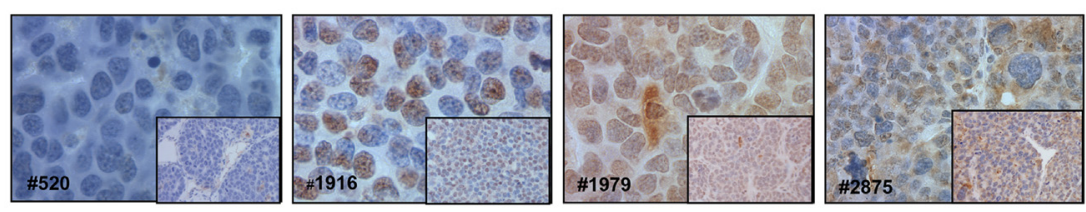

C

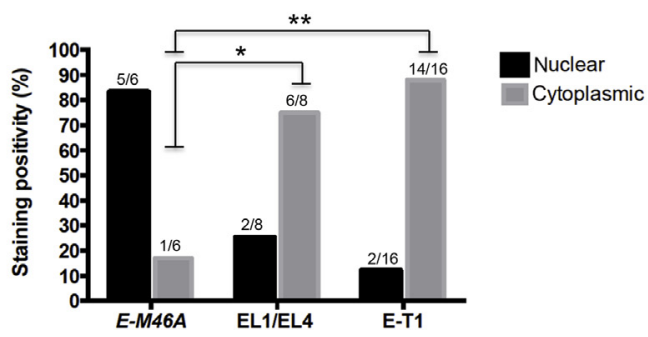

Figure 3 Overexpression of LMW-E is associated with cytoplasmic immunostaining for cyclin $E$ in murine mammary gland tumors. A: Western blot analysis of cyclin E (HE12 antibody) in tumor tissue lysates from 30 cyclin $E$ transgenic mice that expressed EL alone (M46A), EL and the EL4 isoforms (EL1/EL4), or the EL2/3 isoforms of cyclin E (T1) under the control of the mouse mammary tumor virus promoter. Actin was used to control for equal protein loading. B: Representative sections of cyclin $E$ in tumors that expressed the following transgenes (mouse 520) EL1-EL4 (mouse 1916) M46A (mouse 1979, mouse 2875), T1 were subjected to IHC with C-19. C: The percentages of tumor samples scored as positive for nuclear and cytoplasmic cyclin E immunoreactivity in M46A-, EL1/EL4-, and T1-expressing and cyclin E-mice. $n=6 \mathrm{M} 46 \mathrm{~A}$ mice $(\mathbf{A}) ; n=8 \mathrm{EL} 1 / \mathrm{EL} 4$ mice $(\mathbf{A})$; $n=16 \mathrm{~T} 1$ (A). ${ }^{*} P<0.05,{ }^{*} P<0.0005$ for cytoplasmic staining in $\mathrm{LMW}-\mathrm{E}-$ expressing versus cyclin E-negative tumors. Original magnification: $\times 400$ (B, main images); $\times 200$ (B, insets). EL, full-length cyclin $\mathrm{E}$; IHC, immunohistochemical; LMWE, low molecular weight cyclin $\mathrm{E}$. 
cyclin E expression, both on Western blot and IHC analyses. Transgenic mouse line 1916, which was engineered with only the EL, expressed predominately the EL on Western blot analysis and nuclear staining on IHC analysis. Mice 1979 and 2875, engineered with LMW-E transgene, both showed expression of LMW-E by Western blot analysis and cytoplasmic staining by IHC. In addition, IHC staining of tumors from full-length and LMW-E transgenic mice revealed that all tumor tissues that expressed LMW-E (as detected by Western blot analysis) had cyclin E reactivity in the cytoplasm, whereas tumors expressing EL had cyclin E reactivity in the nucleus (Figure 3). Together, these data suggested that the C-19 antibody could detect cyclin E expression and localization by IHC and corresponded with Western blot expression of cyclin E.

\section{Expression of Cyclin E Correlates with Expression of $\mathrm{p}-\mathrm{CDK} 2$ in Breast Cancer Cell Lines}

The major function of cyclin $\mathrm{E}$ is to form a catalytic complex with CDK2, resulting in the activation of that complex by the phosphorylation of CDK2. ${ }^{39}$ Hence, the presence of phospho-CDK2 in cells is indicative of the activated CDK2/ cyclin E complex. Previously, we showed that LMW-E formed an active complex in the cytoplasm of breast cancer cells with the use of fractionation, followed by Western blot and kinase analyses. ${ }^{35}$ Here, we asked if p-CDK2 could be detected in the cytoplasm of breast cancer cells that express LMW-E forms. To this end, we subjected cell blocks from each of the four breast cancer cell lines to a p-CDK2 antibody (Supplemental Figure S9). The results revealed

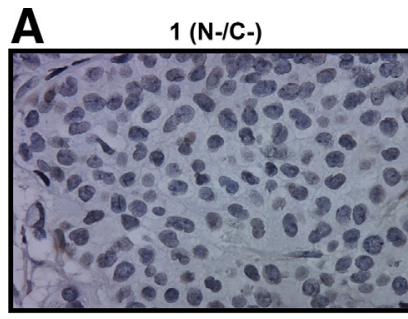

B

Cyclin E

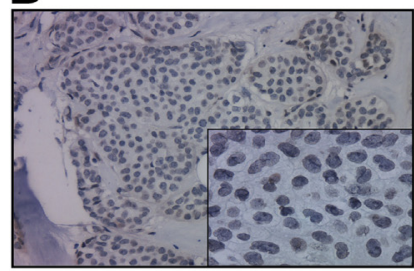

D Cyclin E

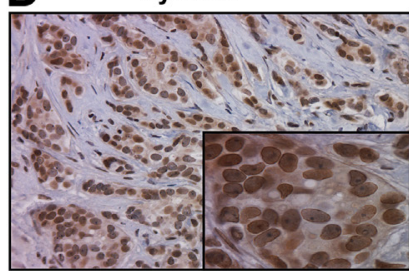

$\mathbf{F}$

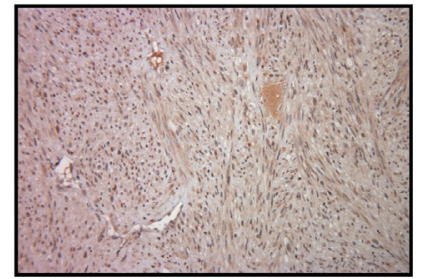

$2(\mathrm{~N}+/ \mathrm{C}-)$

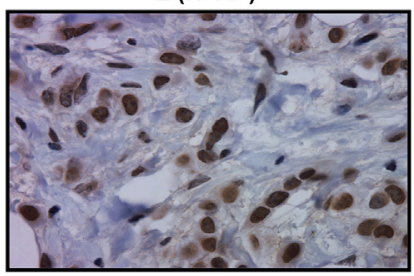

p-CDK2

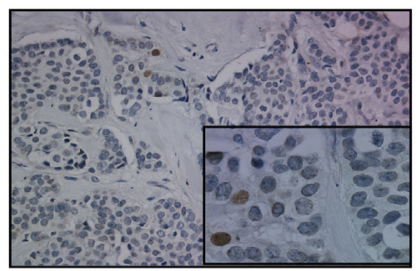

p-CDK2

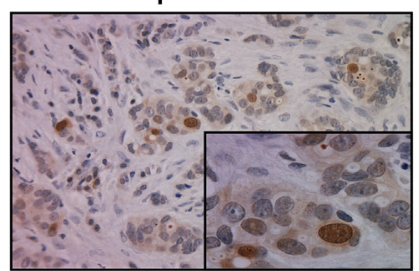

G

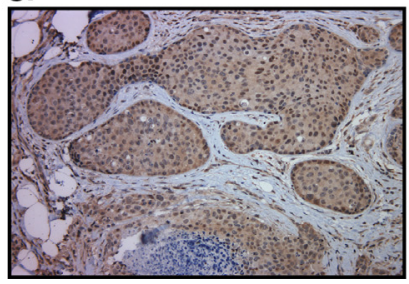

$3(\mathrm{~N}+\mathrm{C}+)$

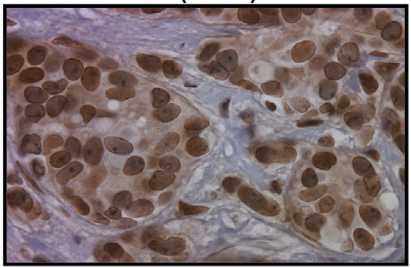

C

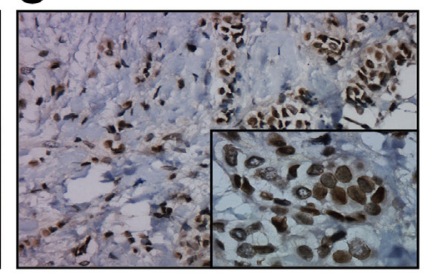

E Cyclin E

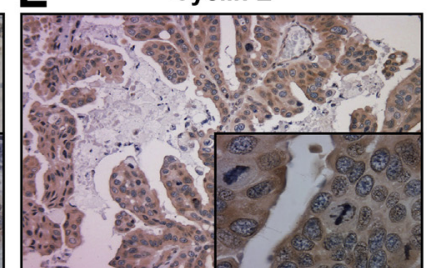

H

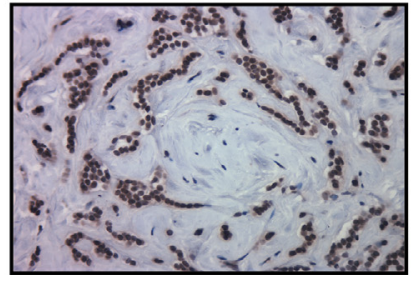

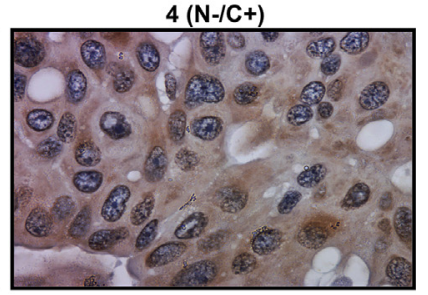

p-CDK2

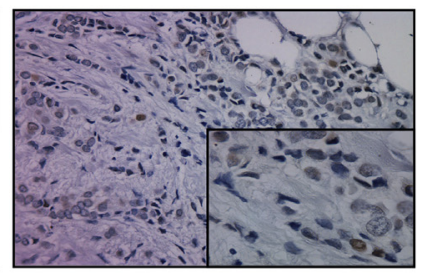

p-CDK2
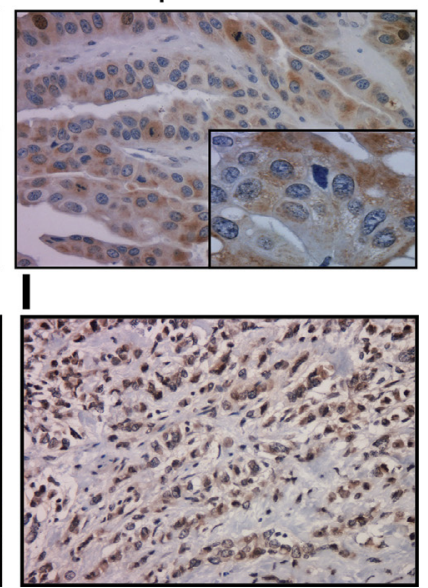

Figure 4 Cytoplasmic staining of cyclin E and p-CDK2 in human breast tumor samples. A: Representative images of the four distinct cyclin E immunostaining phenotypes. The four different cyclin $\mathrm{E}$ phenotypes are distinguished according to the predominance of nuclear or cytoplasmic localization of cyclin $\mathrm{E}$ as follows: phenotype 1 indicates negative staining for $\mathrm{N}$ or $\mathrm{C}$ cyclin $\mathrm{E}\left(\mathrm{N}^{-} / \mathrm{C}^{-}\right)$; phenotype 2, positive $\mathrm{N}$ staining and negative or weak $\mathrm{C}$ staining $\left(\mathrm{N}^{+} / \mathrm{C}^{-}\right)$; phenotype 3, positive $\mathrm{N}$ and $\mathrm{C}\left(\mathrm{N}^{+} / \mathrm{C}^{+}\right)$; phenotype 4, positive $\mathrm{C}$ staining and negative or weak $\mathrm{N}$ staining $\left(\mathrm{N}^{-} / \mathrm{C}^{+}\right)$. B-E: Representative images of immunohistochemical staining for cyclin $\mathrm{E}$ in four distinct patterns and correlation with expression of $\mathrm{p}$-CDK2. Specifically, cyclin $\mathrm{E}$ and corresponding $\mathrm{p}$-CDK2 staining for phenotype $1\left(\mathrm{~N}^{-} / \mathrm{C}^{-} ; \mathbf{B}\right)$, phenotype $2\left(\mathrm{~N}^{+} / \mathrm{C}^{-} ; \mathrm{C}\right)$, phenotype $3\left(\mathrm{~N}^{+} / \mathrm{C}^{+} ; \mathrm{D}\right)$, and phenotype $4\left(\mathrm{~N}^{-} / \mathrm{C}^{+} ; \mathrm{E}\right)$. Table 4 shows significant positive correlation of cytoplasmic staining of cyclin $\mathrm{E}$ and $\mathrm{p}$-CDK2 expression in the 1676 human breast tumor samples examined. $\mathbf{F}-\mathbf{I}$ : Variation in cyclin $\mathrm{E}$ expression according to histologic subtypes of breast carcinomas. F: Sarcomatoid carcinoma sample with a phenotype $4\left(\mathrm{~N}^{-} / \mathrm{C}^{+}\right)$cyclin E staining. G: High-grade invasive ductal carcinoma sample with a phenotype $3\left(\mathrm{~N}^{+} / \mathrm{C}^{+}\right)$cyclin E staining. $\mathrm{H}$ : Well-differentiated invasive lobular carcinoma with a phenotype $2\left(\mathrm{~N}^{+} / \mathrm{C}^{-}\right) \mathrm{cyclin} \mathrm{E}$ staining. I: High-grade invasive lobular carcinoma with a phenotype $4\left(\mathrm{~N}^{-} / \mathrm{C}^{+}\right)$cyclin E staining. Original magnification: $\times 400(\mathbf{A}) ; \times 100(\mathbf{B}-\mathbf{E}$, main images); $\times 400$ (B-E, insets); $\times 200$ (F-I). C, cytoplasmic; N, nuclear; p-CDK2, phospho-cyclin-dependent kinase 2. 
that, although nuclear p-CDK2 was detected in all four cell lines, the cytoplasmic p-CDK2 was detected only in those cell lines that also expressed the LMW-E.

\section{Expression of Cyclin E Correlates with Expression of $\mathrm{p}$-CDK2 in Human Breast Tumors}

Next, we examined the expression of both cyclin E and p-CDK2 in human breast tumor samples. We analyzed TMA samples from two different patient cohorts with stage I to III breast cancer $(n=1676)$ (Table 1$)$. Cyclin E staining results revealed that 171 samples $(10.2 \%)$ were negative for any cyclin E staining (phenotype 1), whereas 484 samples $(28.9 \%)$ were positive for nuclear staining of cyclin E (phenotype 2), 350 samples (20.9\%) were positive for both nuclear and cytoplasmic staining of cyclin $\mathrm{E}$ (phenotype 3), and 671 samples (40\%) were positive for cytoplasmic staining of cyclin E (phenotype 4) (Table 1). Representative images of the four immunostaining patterns of cyclin E in tumor samples are shown in Figure 4A. All patient tumor samples were also stained and scored for cytoplasmic localization of p-CDK2, and results revealed that, of the 1676 cases, 678 (40.4\%) stained for nuclear and $998(59.6 \%)$ stained for cytoplasmic p-CDK2 (Table 1). Further, there was a strong correlation between cytoplasmic cyclin E staining and cytoplasmic pCDK2 staining in our patient cohorts $(P<0.0001)$ (Table 4; Figure 4, B-E). Specifically, $85.1 \%$ of all patients with cytoplasmic cyclin E expression also had cytoplasmic pCDK2 expression, and $80.3 \%$ of all patients without cytoplasmic cyclin E expression also lacked cytoplasmic pCDK2 expression.

\section{Expression of Cyclin E and p-CDK2 Correlates with High-Grade, $\mathrm{HER}^{+}{ }^{+}$and ER/PR ${ }^{-}$Breast Tumors}

The cytoplasmic expression of cyclin E (phenotypes 3 and 4) and/or p-CDK2 was significantly correlated with high histologic grade (ie, grade III) $(P<0.0001)$. In contrast, was no significant association was found between nuclear cyclin E expression (phenotype 2) and high histologic grade (Table 5, Supplemental Table S3). These results suggested that breast cancer patients with predominantly cytoplasmic cyclin E and p-CDK2 expression have clinicopathologic characteristics associated with a poor prognosis. Univariate analysis revealed that cytoplasmic expression of cyclin $\mathrm{E}$ and/or p-CDK2 was positively correlated with HER2 status

Table 4 Correlation between Cytoplasmic Cyclin E Staining and Cytoplasmic pCDK2 Staining

\begin{tabular}{llll}
\hline Staining & $\begin{array}{l}\text { Cyclin } \\
\text { E-negative }\end{array}$ & $\begin{array}{l}\text { Cyclin } \\
\text { E-positive }\end{array}$ & $P$ value \\
\hline p-CDK2-negative & $526(80.3)$ & $152(14.9)$ & $<0.0001$ \\
p-CDK2-positive & $129(19.7)$ & $869(85.1)$ & \\
\hline
\end{tabular}

Data are expressed as $n(\%)$ unless otherwise specified.

p-CDK2, phospho-cyclin-dependent kinase 2. and inversely correlated with ER and PR status (Table 5); this finding was most significant for cases with cytoplasmic expression of both cyclin E and p-CDK2 $(P<0.0001)$.

We also examined cyclin $\mathrm{E}$ expression according to different histologic subtypes of invasive breast carcinoma (Figure 4, F-I, Table 6). The majority of the cases examined [1437 (85.9\%)] were invasive ductal carcinoma (IDC). The remaining 235 cases $(14.1 \%)$ consisted of invasive lobular $(n=148)$, mixed ductal-lobular $(n=24)$, tubular $(n=16)$, mucinous $(n=13)$, cribriform $(n=10)$, medullary $(n=8)$, papillary $(n=10)$, and micropapillary $(n=6)$ carcinoma. Table 6 shows the four cyclin $\mathrm{E}$ immunostaining patterns according to histologic subtype of breast cancer [nuclear $(\mathrm{N})$ or cytoplasmic (C)]. Of the 1437 cases of IDC, 509 (35.4\%) were of cyclin $\mathrm{E}$ phenotype 1 or $2\left(\mathrm{~N}^{-} / \mathrm{C}^{-}\right.$or $\left.\mathrm{N}^{+} / \mathrm{C}^{-}\right)$, whereas $928(64.6 \%)$ were of phenotype 3 or $4\left(\mathrm{~N}^{+} / \mathrm{C}^{+}\right.$or $\mathrm{N}^{-} / \mathrm{C}^{+}$). In comparison, of the 148 lobular carcinomas, 97 $(65.5 \%)$ were of cyclin E phenotype 1 or $2\left(\mathrm{~N}^{-} / \mathrm{C}^{-}\right.$or $\mathrm{N}^{+} /$ $\left.\mathrm{C}^{-}\right)$, whereas $51(34.5 \%)$ were of phenotype 3 or $4\left(\mathrm{~N}^{+} / \mathrm{C}^{+}\right.$or $\left.\mathrm{N}^{-} / \mathrm{C}^{+}\right)$. The difference in staining between these two subtypes was significant $(P<0.0001)$. Although we found differences in cyclin E expression among the subgroups of IDC patients, further assessment of the statistical correlations among those patients was not possible because of the relatively low number of samples.

\section{Outcome Analysis}

Kaplan-Meier RFS and OS curves as a function of the combination of cytoplasmic cyclin $\mathrm{E}$ and $\mathrm{pCDK} 2$ staining are shown in Figure 5. Lack of cytoplasmic staining for cyclin E and pCDK2 was associated with a good prognosis, whereas presence of cytoplasmic staining for both proteins was correlated with a significantly worse prognosis $(P<0.0001)$.

\section{Multivariable Analysis}

The multivariable analysis of factors predictive of RFS is presented in Table 3. For these analyses, all factors shown in Table 1 were initially included in the model as potential risk factors. Cytoplasmic cyclin E and cytoplasmic pCDK2 as individual variables were highly significant. When cytoplasmic cyclin E and cytoplasmic pCDK2 were combined as one variable, they outperformed all other clinical and pathologic variables, as reflected in both the significant $P$ values and the higher hazard ratios.

\section{Discussion}

Here, we examined the relation between LMW-E measured by Western blot analysis and IHC in breast cancer cell lines and mammary tumors from cyclin $\mathrm{E}$ transgenic mice. We found that LMW-E expression on Western blot analysis correlated with cytoplasmic staining for cyclin E on IHC. Because LMW-E lacks the nuclear localization signal of EL, we investigated its subcellular localization and 
Table 5 Combined Cytoplasmic Staining of Breast Tumor Samples for Cyclin E and p-CDK2 according to Histologic Grade and ER, PR, and HER2 Status

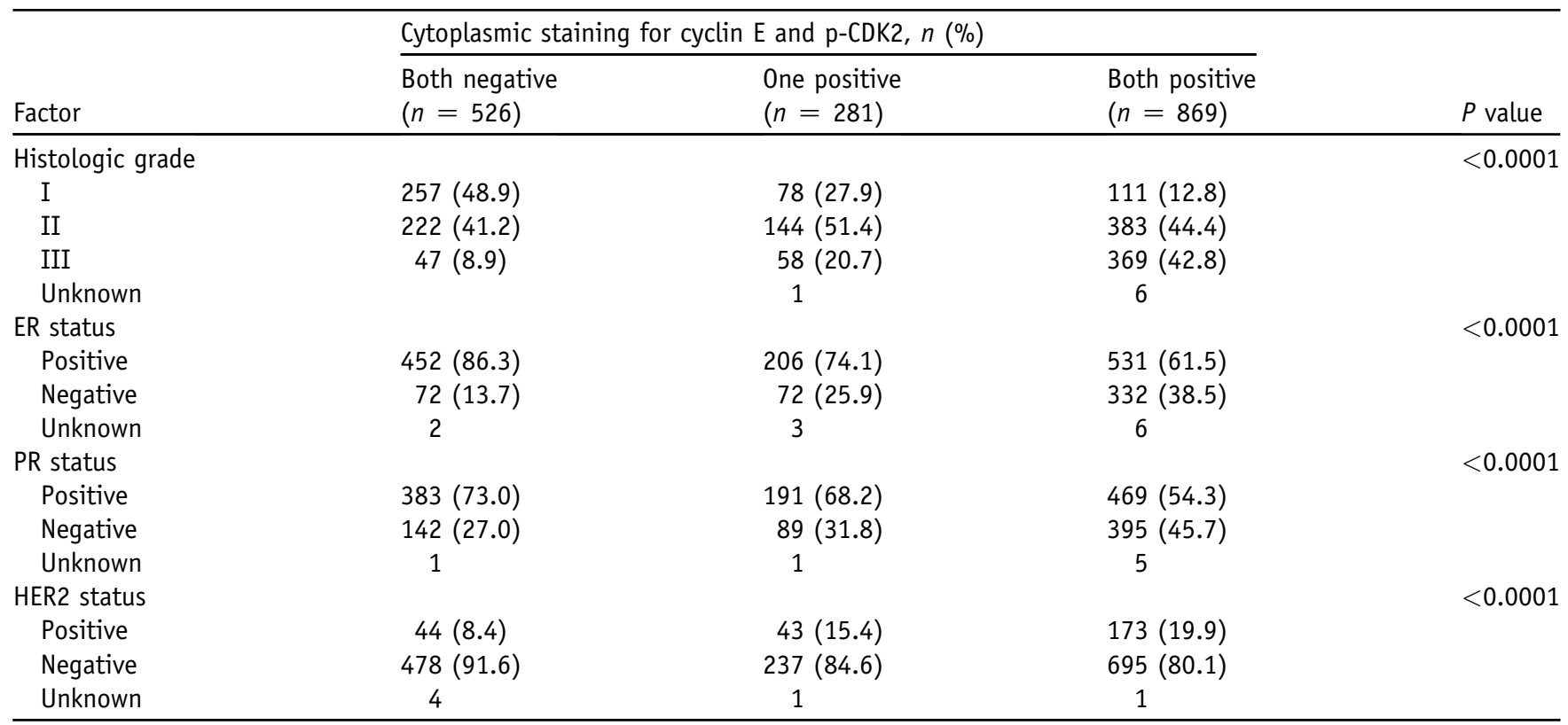

Values are $n(\%)$ unless otherwise specified.

ER, estrogen receptor; HER2, human epidermal growth factor receptor 2; p-CDK2, phospho-cyclin-dependent kinase 2; PR, progesterone receptor.

reported that LMW-E accumulates in the cytoplasm, where it binds CDK2 and retains kinase activity. ${ }^{39}$ Cytoplasmic cyclin E was associated with cytoplasmic staining for $\mathrm{p}$ CDK2, as a measure of cyclin E-associated kinase activity. Concordant with the cytoplasmic cyclin E expression, cytoplasmic p-CDK2 expression was strongly associated with high histologic grade. We also found that cytoplasmic expression of both cyclin E and p-CDK2 was most significantly associated with ER negativity, PR negativity, and HER2 positivity $(P<0.0001)$. These findings support that LMW-E, the tumorigenic form of cyclin E, preferentially accumulates in the cytoplasm and interacts with its kinase partner CDK2.

In the current study, we examined cyclin E expression patterns in the largest cohort of breast cancer patients reported to date. We observed cytoplasmic cyclin $\mathrm{E}$ expression in $60.9 \%$ of breast cancer patients and nuclear cyclin $\mathrm{E}$ expression in $39.1 \%$. Comparison of our results with those of previous studies is difficult because until now, cyclin E expression has been graded according to the percentage of tumor cell nuclei that exhibit positive staining. $3,5,6,35,36,38,40-43$ Although investigators have observed some cytoplasmic cyclin E staining, they only considered nuclear staining in their analysis. $3,42,44,56$ Another reason for the difference in magnitude of cyclin E expression in the cytoplasm between our investigation and previous studies may be related to differences in scoring systems and immunostaining procedures, such as the antigen retrieval buffer and its $\mathrm{pH}$ level and the antibodies used, as well as differences in the number and/or characteristics of

Table 6 Cyclin E Phenotypes according to Histopathologic Subtypes of Breast Tumors

\begin{tabular}{|c|c|c|c|c|c|}
\hline \multirow[b]{2}{*}{ Histopathologic subtype* } & \multicolumn{4}{|c|}{ Cyclin E phenotype } & \multirow[b]{2}{*}{$P$ value } \\
\hline & $1(n=171)$ & $2(n=484)$ & $3(n=350)$ & $4(n=671)$ & \\
\hline 1 & $149(87.13)$ & $360(74.38)$ & $307(88.47)$ & $621(92.69)$ & $<0.0001$ \\
\hline 3 & $0(0)$ & $18(3.72)$ & $1(0.29)$ & $5(0.75)$ & \\
\hline 4 & $0(0)$ & $11(2.27)$ & $2(0.58)$ & $3(0.45)$ & \\
\hline 5 & $3(1.75)$ & $6(1.24)$ & $2(0.58)$ & $2(0.3)$ & \\
\hline 8 & $0(0)$ & $2(0.41)$ & $2(0.58)$ & $6(0.9)$ & \\
\hline 9 & $0(0)$ & $1(0.21)$ & $1(0.29)$ & $4(0.6)$ & \\
\hline Unknown & & & 3 & 1 & \\
\hline
\end{tabular}

Data are expressed as $n(\%)$ unless otherwise specified.

*Histologic subtypes are as follows: 1, invasive ductal carcinoma; 2, invasive lobular carcinoma; 3, mixed ductal-lobular carcinoma; 4, tubular carcinoma; 5, mucinous carcinoma; 6, cribriform carcinoma; 7, medullary carcinoma; 8, papillary carcinoma; 9, micropapillary carcinoma. 

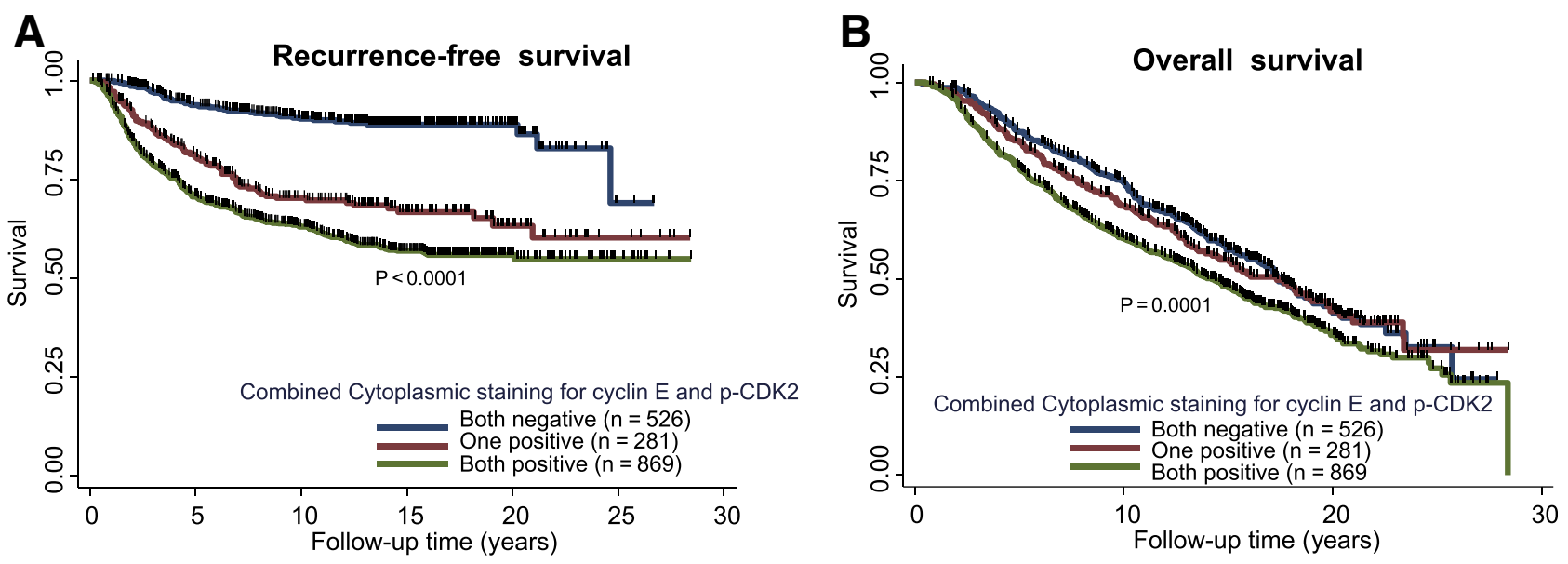

Figure 5 Kaplan-Meier survival plots demonstrating the association between combined cytoplasmic staining for cyclin E and p-CDK2 and breast cancer recurrence-free survival (A) and breast cancer overall survival (B). p-CDK2, phospho-cyclin-dependent kinase 2.

the study patients. Therefore, standardization of the IHC method and scoring system is required for future studies and translation into routine clinical care.

Cyclin E overexpression is reported to be associated with aggressive tumor phenotypes. In our study, immunostaining for cytoplasmic cyclin E was strongly associated with high tumor grade. This finding was similar to those of previous studies that reported a relation between cyclin $\mathrm{E}$ overexpression and high histologic grade..$^{2,3,5,8,40-44} \mathrm{We}$ also found a strong association between histologic subtype and cyclin $\mathrm{E}$ immunostaining pattern. IDC and invasive lobular carcinoma (ILC) are the most common histologic subtypes of all invasive breast carcinomas, so we determined the staining distribution between these subtypes, because they encompass most breast cancers. We found that 509 IDC samples (35.4\%) had no staining or nuclear only staining, whereas 928 samples (64.6\%) had cytoplasmic staining. In comparison, among ILC samples, we observed no staining or nuclear only staining in 97 $(65.5 \%)$ and cytoplasmic staining in 51 (34.5\%). The staining differences between these two subtypes were significant $(P<0.0001)$.

Two previous studies have examined the expression of cyclin $\mathrm{E}$ and related proteins according to histologic breast cancer subtype. ${ }^{41,49}$ The first included 40 patients as follows: 21 with IDC and 19 with ILC. ${ }^{49}$ Although the investigators observed immunoreactivity for cyclin $\mathrm{E}$ in both types of carcinoma cells and in adjacent nonneoplastic ductal cells, they did not see a marked difference in cyclin E expression between the two subtypes. ${ }^{49}$ The second study included 66 patients as follows: 59 with IDC and 7 with ILC. In contrast with the first study, 9 of the 66 cases had cyclin $\mathrm{E}$ overexpression. In particular, all of the lobular carcinomas were negative for cyclin E. ${ }^{41}$ The main reasons for the discrepancy between these two studies are the definition of cyclin E positivity and the small study populations.
In conclusion, we show that the pattern of cytoplasmic staining for cyclin $\mathrm{E}$ in conjunction with cytoplasmic p-CDK2 supports that expression of LMW-E, the tumorigenic form of cyclin E, may be deregulated in breast cancer cells not just at the expression level but also by altered cellular localization. IHC is a simple, inexpensive, reliable method of assessing cyclin $\mathrm{E}$ expression. We propose that both cyclin $\mathrm{E}$ and $\mathrm{p}-\mathrm{CDK} 2$ are important markers for breast cancer and are associated with other tumor markers such as tumor grade, ER, PR, HER2 status, and are highly correlated with poor patient outcome.

\section{Acknowledgments}

We thank Dana Richardson for assisting with Western blot analysis and cell culturing and the Breast Tumor Bank of the MD Anderson Cancer Center for providing us the clinical samples.

C.K., K.K.H., and K.K. conceived and performed the experiments; A.B., A.S., S.A., and O.A. performed the experiments and analyzed the data; T.B. and J.S. performed the experiments; M.Y. collected the data and performed the statistical analysis; A.A. analyzed the data. All authors wrote the paper and approved the final submitted version.

\section{Supplemental Data}

Supplemental material for this article can be found at http://dx.doi.org/10.1016/j.ajpath.2016.02.024.

\section{References}

1. Hwang HC, Clurman BE: Cyclin E in normal and neoplastic cell cycles. Oncogene 2005, 24:2776-2786

2. Bales E, Mills L, Milam N, McGahren-Murray M, Bandyopadhyay D, Chen D, Reed JA, Timchenko N, van den Oord JJ, Bar-Eli M, Keyomarsi K, Medrano EE: The low molecular 
weight cyclin $\mathrm{E}$ isoforms augment angiogenesis and metastasis of human melanoma cells in vivo. Cancer Res 2005, 65:692-697

3. Chappuis PO, Donato E, Goffin JR, Wong N, Begin LR, Kapusta LR, Brunet JS, Porter P, Foulkes WD: Cyclin E expression in breast cancer: predicting germline BRCA1 mutations, prognosis and response to treatment. Ann Oncol 2005, 16:735-742

4. Davidson B, Skrede M, Silins I, Shih IeM, Trope CG, Florenes VA: Low-molecular weight forms of cyclin E differentiate ovarian carcinoma from cells of mesothelial origin and are associated with poor survival in ovarian carcinoma. Cancer 2007, 110:1264-1271

5. Han S, Park K, Bae BN, Kim KH, Kim HJ, Kim YD, Kim HY: Prognostic implication of cyclin E expression and its relationship with cyclin D1 and p27Kip1 expression on tissue microarrays of node negative breast cancer. J Surg Oncol 2003, 83:241-247

6. Kim HK, Park IA, Heo DS, Noh DY, Choe KJ, Bang YJ, Kim NK: Cyclin E overexpression as an independent risk factor of visceral relapse in breast cancer. Eur J Surg Oncol 2001, 27:464-471

7. Muller-Tidow C, Metzger R, Kugler K, Diederichs S, Idos G, Thomas M, Dockhorn-Dworniczak B, Schneider PM, Koeffler HP, Berdel WE, Serve H: Cyclin E is the only cyclindependent kinase 2-associated cyclin that predicts metastasis and survival in early stage non-small cell lung cancer. Cancer Res 2001, 61:647-653

8. Libertini SJ, Robinson BS, Dhillon NK, Glick D, George M, Dandekar S, Gregg JP, Sawai E, Mudryj M: Cyclin E both regulates and is regulated by calpain 2, a protease associated with metastatic breast cancer phenotype. Cancer Res 2005, 65:10700-10708

9. Caldon CE, Musgrove EA: Distinct and redundant functions of cyclin E1 and cyclin E2 in development and cancer. Cell Div 2010, 5:2

10. Moroy T, Geisen C: Cyclin E. Int J Biochem Cell Biol 2004, 36: $1424-1439$

11. Akli S, Van Pelt CS, Bui T, Multani AS, Chang S, Johnson D, Tucker S, Keyomarsi K: Overexpression of the low molecular weight cyclin $\mathrm{E}$ in transgenic mice induces metastatic mammary carcinomas through the disruption of the ARF-p53 pathway. Cancer Res 2007, 67:7212-7222

12. Porter DC, Zhang N, Danes C, McGahren MJ, Harwell RM, Faruki S, Keyomarsi K: Tumor-specific proteolytic processing of cyclin $\mathrm{E}$ generates hyperactive lower-molecular-weight forms. Mol Cell Biol 2001, 21:6254-6269

13. Bagheri-Yarmand R, Biernacka A, Hunt KK, Keyomarsi K: Low molecular weight cyclin E overexpression shortens mitosis, leading to chromosome missegregation and centrosome amplification. Cancer Res 2010, 70:5074-5084

14. Duong MT, Akli S, Macalou S, Biernacka A, Debeb BG, Yi M, Hunt KK, Keyomarsi K: Hbo1 is a cyclin E/CDK2 substrate that enriches breast cancer stem-like cells. Cancer Res 2013, 73: $5556-5568$

15. Akli S, Van Pelt CS, Bui T, Meijer L, Keyomarsi K: Cdk2 is required for breast cancer mediated by the low-molecular-weight isoform of cyclin E. Cancer Res 2011, 71:3377-3386

16. Bagheri-Yarmand R, Nanos-Webb A, Biernacka A, Bui $T$, Keyomarsi K: Cyclin E deregulation impairs mitotic progression through premature activation of Cdc25C. Cancer Res 2010, 70: 5085-5095

17. Mombelli S, Cochaud S, Merrouche Y, Garbar C, Antonicelli F, Laprevotte E, Alberici G, Bonnefoy N, Eliaou JF, Bastid J, Bensussan A, Giustiniani J: IL-17A and its homologs IL-25/IL$17 \mathrm{E}$ recruit the c-RAF/S6 kinase pathway and the generation of pro-oncogenic LMW-E in breast cancer cells. Sci Rep 2015, 5: 11874

18. Tokai Y, Maeda S, Yamaguchi J, Uga T, Hayashida N, Taniguchi K, Eguchi S, Kanematsu T: Cyclin E low-molecular-weight isoform as a predictor of breast cancer in Japanese women. Int Surg 2011, 96: 245-253

19. Montazeri H, Bouzari S, Azadmanesh K, Ostad SN, Ghahremani MH: Divergent behavior of cyclin E and its low molecular weight isoforms to progesterone-induced growth inhibition in MCF-7 cells. Adv Biomed Res 2015, 4:16

20. Taneja P, Maglic D, Kai F, Zhu S, Kendig RD, Fry EA, Inoue K: Classical and novel prognostic markers for breast cancer and their clinical significance. Clin Med Insights Oncol 2010, 4:15-34

21. Rath SL, Senapati S: Why are the truncated cyclin Es more effective CDK2 activators than the full-length isoforms? Biochemistry 2014, 53:4612-4624

22. Loeb KR, Chen X: Too much cleavage of cyclin E promotes breast tumorigenesis. PLoS Genet 2012, 8:e1002623

23. Moore JD: In the wrong place at the wrong time: does cyclin mislocalization drive oncogenic transformation? Nat Rev Cancer 2013, 13:201-208

24. Bedrosian I, Lu KH, Verschraegen C, Keyomarsi K: Cyclin E deregulation alters the biologic properties of ovarian cancer cells. Oncogene 2004, 23:2648-2657

25. Milne AN, Carvalho R, Jansen M, Kranenbarg EK, van de Velde CJ, Morsink FM, Musler AR, Weterman MA, Offerhaus GJ: Cyclin E low molecular weight isoforms occur commonly in early-onset gastric cancer and independently predict survival. J Clin Pathol 2008, 61: $311-316$

26. Corin I, Di Giacomo MC, Lastella P, Bagnulo R, Guanti G, Simone C: Tumor-specific hyperactive low-molecular-weight cyclin $\mathrm{E}$ isoforms detection and characterization in non-metastatic colorectal tumors. Cancer Biol Ther 2006, 5:198-203

27. Corin I, Larsson L, Bergstrom J, Gustavsson B, Derwinger K: A study of the expression of Cyclin E and its isoforms in tumor and adjacent mucosa, correlated to patient outcome in early colon cancer. Acta Oncol 2010, 49:63-69

28. Zhou YJ, Xie YT, Gu J, Yan L, Guan GX, Liu X: Overexpression of cyclin E isoforms correlates with poor prognosis in rectal cancer. Eur J Surg Oncol 2011, 37:1078-1084

29. Koutsami MK, Tsantoulis PK, Kouloukoussa M, Apostolopoulou K, Pateras IS, Spartinou Z, Drougou A, Evangelou K, Kittas C, Bartkova J, Bartek J, Gorgoulis VG: Centrosome abnormalities are frequently observed in non-small-cell lung cancer and are associated with aneuploidy and cyclin E overexpression. J Pathol 2006, 209: $512-521$

30. Nauman A, Turowska O, Poplawski P, Master A, Tanski Z, Puzianowska-Kuznicka M: Elevated cyclin E level in human clear cell renal cell carcinoma: possible causes and consequences. Acta Biochim Pol 2007, 54:595-602

31. Keyomarsi K, Tucker SL, Buchholz TA, Callister M, Ding Y, Hortobagyi GN, Bedrosian I, Knickerbocker C, Toyofuku W, Lowe M, Herliczek TW, Bacus SS: Cyclin E and survival in patients with breast cancer. N Engl J Med 2002, 347:1566-1575

32. Wingate $\mathrm{H}$, Zhang $\mathrm{N}$, McGarhen MJ, Bedrosian I, Harper JW, Keyomarsi K: The tumor-specific hyperactive forms of cyclin E are resistant to inhibition by p21 and p27. J Biol Chem 2005, 280: $15148-15157$

33. Akli S, Zheng PJ, Multani AS, Wingate HF, Pathak S, Zhang N, Tucker SL, Chang S, Keyomarsi K: Tumor-specific low molecular weight forms of cyclin $\mathrm{E}$ induce genomic instability and resistance to p21, p27, and antiestrogens in breast cancer. Cancer Res 2004, 64: 3198-3208

34. Akli S, Bui T, Wingate H, Biernacka A, Moulder S, Tucker SL, Hunt KK, Keyomarsi K: Low-molecular-weight cyclin E can bypass letrozole-induced G1 arrest in human breast cancer cells and tumors. Clin Cancer Res 2010, 16:1179-1190

35. Wingate H, Puskas A, Duong M, Bui T, Richardson D, Liu Y, Tucker SL, Van Pelt C, Meijer L, Hunt K, Keyomarsi K: Low molecular weight cyclin $\mathrm{E}$ is specific in breast cancer and is associated with mechanisms of tumor progression. Cell Cycle 2009, 8: $1062-1068$

36. Duong MT, Akli S, Wei C, Wingate HF, Liu W, Lu Y, Yi M, Mills GB, Hunt KK, Keyomarsi K: LMW-E/CDK2 deregulates acinar morphogenesis, induces tumorigenesis, and associates with the 
activated b-Raf-ERK1/2-mTOR pathway in breast cancer patients. PLoS Genet 2012, 8:e1002538

37. Nanos-Webb A, Bui T, Karakas C, Zhang D, Carey JP, Mills GB, Hunt KK, Keyomarsi K: PKCiota promotes ovarian tumor progression through deregulation of cyclin E. Oncogene 2016, 35: $2428-2440$

38. Hunt KK, Keyomarsi K: Cyclin E as a prognostic and predictive marker in breast cancer. Semin Cancer Biol 2005, 15:319-326

39. Delk NA, Hunt KK, Keyomarsi K: Altered subcellular localization of tumor-specific cyclin $\mathrm{E}$ isoforms affects cyclin-dependent kinase 2 complex formation and proteasomal regulation. Cancer Res 2009, 69: $2817-2825$

40. Voduc D, Nielsen TO, Cheang MC, Foulkes WD: The combination of high cyclin E and Skp2 expression in breast cancer is associated with a poor prognosis and the basal phenotype. Hum Pathol 2008, 39: $1431-1437$

41. Pillay K, McCleod H, Chetty R, Hall P: A study to investigate the role of p27 and cyclin E immunoexpression as a prognostic factor in early breast carcinoma. World J Surg Oncol 2011, 9:31

42. Du J, Du Q, Zhang Y, Sajdik C, Ruan Y, Tian XX, Fang WG: Expression of cell-cycle regulatory proteins BUBR1, MAD2, Aurora $\mathrm{A}$, cyclin $\mathrm{A}$ and cyclin $\mathrm{E}$ in invasive ductal breast carcinomas. Histol Histopathol 2011, 26:761-768

43. Waltersson MA, Askmalm MS, Nordenskjold B, Fornander T, Skoog L, Stal O: Altered expression of cyclin E and the retinoblastoma protein influences the effect of adjuvant therapy in breast cancer. Int J Oncol 2009, 34:441-448

44. Donnellan R, Kleinschmidt I, Chetty R: Cyclin E immunoexpression in breast ductal carcinoma: pathologic correlations and prognostic implications. Hum Pathol 2001, 32:89-94

45. Foulkes WD, Brunet JS, Stefansson IM, Straume O, Chappuis PO, Begin LR, Hamel N, Goffin JR, Wong N, Trudel M, Kapusta L, Porter P, Akslen LA: The prognostic implication of the basal-like (cyclin E high/p27 low/p53+/glomeruloid-microvascular-proliferation+) phenotype of BRCA1-related breast cancer. Cancer Res 2004, 64:830-835

46. Lindahl T, Landberg G, Ahlgren J, Nordgren H, Norberg T, Klaar S, Holmberg L, Bergh J: Overexpression of cyclin E protein is associated with specific mutation types in the p53 gene and poor survival in human breast cancer. Carcinogenesis 2004, 25: 375-380

47. Bostrom P, Soderstrom M, Palokangas T, Vahlberg T, Collan Y, Carpen O, Hirsimaki P: Analysis of cyclins A, B1, D1 and E in breast cancer in relation to tumour grade and other prognostic factors. BMC Res Notes 2009, 2:140
48. Schraml P, Bucher C, Bissig H, Nocito A, Haas P, Wilber K, Seelig S, Kononen J, Mihatsch MJ, Dirnhofer S, Sauter G: Cyclin E overexpression and amplification in human tumours. J Pathol 2003, 200:375-382

49. Sasano H, Frost AR, Saitoh R, Taniyama Y, Nagura H, Matsunaga G, Takehana K, Kimura M, Silverberg SG: Immunolocalization of cyclins D and E and cyclin dependent kinase (cdk) 2 and 4 in human breast carcinoma. Anticancer Res 1997, 17:3685-3690

50. Porter PL, Barlow WE, Yeh IT, Lin MG, Yuan XP, Donato E, Sledge GW, Shapiro CL, Ingle JN, Haskell CM, Albain KS, Roberts JM, Livingston RB, Hayes DF: p27(Kip1) and cyclin E expression and breast cancer survival after treatment with adjuvant chemotherapy. J Natl Cancer Inst 2006, 98:1723-1731

51. Scaltriti M, Eichhorn PJ, Cortes J, Prudkin L, Aura C, Jimenez J, Chandarlapaty S, Serra V, Prat A, Ibrahim YH, Guzman M, Gili M, Rodriguez O, Rodriguez S, Perez J, Green SR, Mai S, Rosen N, Hudis C, Baselga J: Cyclin E amplification/overexpression is a mechanism of trastuzumab resistance in HER2 + breast cancer patients. Proc Natl Acad Sci U S A 2011, 108:3761-3766

52. Thompson PA, Brewster AM, Kim-Anh D, Baladandayuthapani V, Broom BM, Edgerton ME, Hahn KM, Murray JL, Sahin A, Tsavachidis S, Wang Y, Zhang L, Hortobagyi GN, Mills GB, Bondy ML: Selective genomic copy number imbalances and probability of recurrence in early-stage breast cancer. PLoS One 2011, 6:e23543

53. Wolff AC, Hammond ME, Hicks DG, Dowsett M, McShane LM, Allison KH, Allred DC, Bartlett JM, Bilous M, Fitzgibbons P, Hanna W, Jenkins RB, Mangu PB, Paik S, Perez EA, Press MF, Spears PA, Vance GH, Viale G, Hayes DF; American Society of Clinical Oncology; College of American Pathologists: Recommendations for human epidermal growth factor receptor 2 testing in breast cancer: American Society of Clinical Oncology/College of American Pathologists clinical practice guideline update. J Clin Oncol 2013, 31: 3997-4013

54. Mittendorf EA, Liu Y, Tucker SL, McKenzie T, Qiao N, Akli S, Biernacka A, Liu Y, Meijer L, Keyomarsi K, Hunt KK: A novel interaction between HER2/neu and cyclin E in breast cancer. Oncogene 2010, 29:3896-3907

55. Nanos-Webb A, Jabbour NA, Multani AS, Wingate H, Oumata N, Galons H, Joseph B, Meijer L, Hunt KK, Keyomarsi K: Targeting low molecular weight cyclin E (LMW-E) in breast cancer. Breast Cancer Res Treat 2012, 132:575-588

56. Shaye A, Sahin A, Hao Q, Hunt K, Keyomarsi K, Bedrosian I: Cyclin $\mathrm{E}$ deregulation is an early event in the development of breast cancer. Breast Cancer Res Treat 2009, 115:651-659 